\title{
Investigation of an outbreak of acute illness in a school group visiting Sydney, September 2006
}

\author{
Trish Mannes $^{\mathrm{A}, \mathrm{D}}$, Bradley Forssman ${ }^{\mathrm{A}}$, \\ Leena Gupta ${ }^{\mathrm{A}}$, Mark Ferson ${ }^{\mathrm{B}}$, \\ Simone Christopher ${ }^{\mathrm{B}}$, Jeremy McAnulty ${ }^{\mathrm{C}}$ \\ and Jennie Musto ${ }^{\mathrm{C}}$ \\ ASydney South West Public Health Unit, \\ Sydney South West Area Health Service \\ ${ }^{B}$ South East Sydney Illawarra Public Health Unit, \\ South East Sydney Illawarra Area Health Service \\ ${ }^{\mathrm{C}} N S W$ Department of Health, Communicable Diseases Branch \\ DCorresponding author.Email: trish.mannes@gmail.com
}

\begin{abstract}
Objective: We describe the investigation into an outbreak of acute illness in approximately 40 people attending Darling Harbour in Sydney during a school music camp. Methods: We used three methods, including the Public Health Realtime Emergency Department Surveillance System, to obtain information on the food and travel history of the group and symptoms of the cases rapidly. Results: Forty-five cases of gastroenteritis were identified in people on the bus trip. Most dates of onset of illness were obtained from triage text fields in the NSW Public Health Real Time Emergency Department Surveillance System, and were verified through medical record review and interviews. No causative agent was identified. Conclusion: The investigation suggested person-to-person transmission rather than a point source, and demonstrates how the NSW Public Health Real Time Emergency Department Surveillance System can assist with case finding in public health investigations.
\end{abstract}

In September 2006, NSW Health was notified that up to 40 children on a school bus trip from Queensland were acutely unwell with gastroenteritis. The group was visiting Darling Harbour (a tourist precinct adjacent to the central business district of Sydney) and group members affected were being transported by ambulance to three hospitals in inner Sydney. Preliminary reports suggested that the students might be suffering from a large scale acute poisoning incident. Public health authorities needed to obtain information on the cases rapidly in order to determine a possible cause.

This report describes the features of the public health investigation and the methods used to assess the incident quickly.

\section{Methods}

Three methods were used to obtain information rapidly on the food and travel history of the group, and on the symptoms of affected people in a case series.

Case definition for this investigation was: any person travelling on the bus trip who experienced one or more of the following symptoms between 16 and 29 September 2006: vomiting, nausea, diarrhoea, stomach cramps or abdominal pain.

We interviewed a senior teacher about the travel and food history of the group. Data collected included information on where the group stayed, the meals consumed and the symptoms reported by students, teachers and drivers. Cases occurring before 16 September were identified, including several cases in students whose illness had resolved and who therefore did not present to any of the three Sydney hospitals. The recreation camp was inspected to investigate the possibility of food or water-borne transmission.

We reviewed medical records and interviewed clinicians regarding cases that presented to Hospital 1 to obtain onset dates and symptoms. At Hospital 2, we conducted a medical record review and brief interviews with each affected person. At Hospital 3, the NSW Public Health Real Time Emergency Department Surveillance System (PHREDSS) was used to obtain information recorded in nursing triage notes swiftly. ${ }^{1}$ The triage text field of the PHREDSS included details on disease onset and symptom descriptions, allowing verification of the history of known cases presenting to Hospitals 1 and 2. Further information on cases presenting to Hospital 3 was then obtained by reviewing medical records.

Stool samples were taken from two people who were treated at Hospital 2. These samples were examined by faecal microscopy, bacterial culture and viral studies, including testing for rotavirus and norovirus using both enzyme immunoassay and reverse transcriptase polymerase chain reaction testing. ${ }^{2}$ 


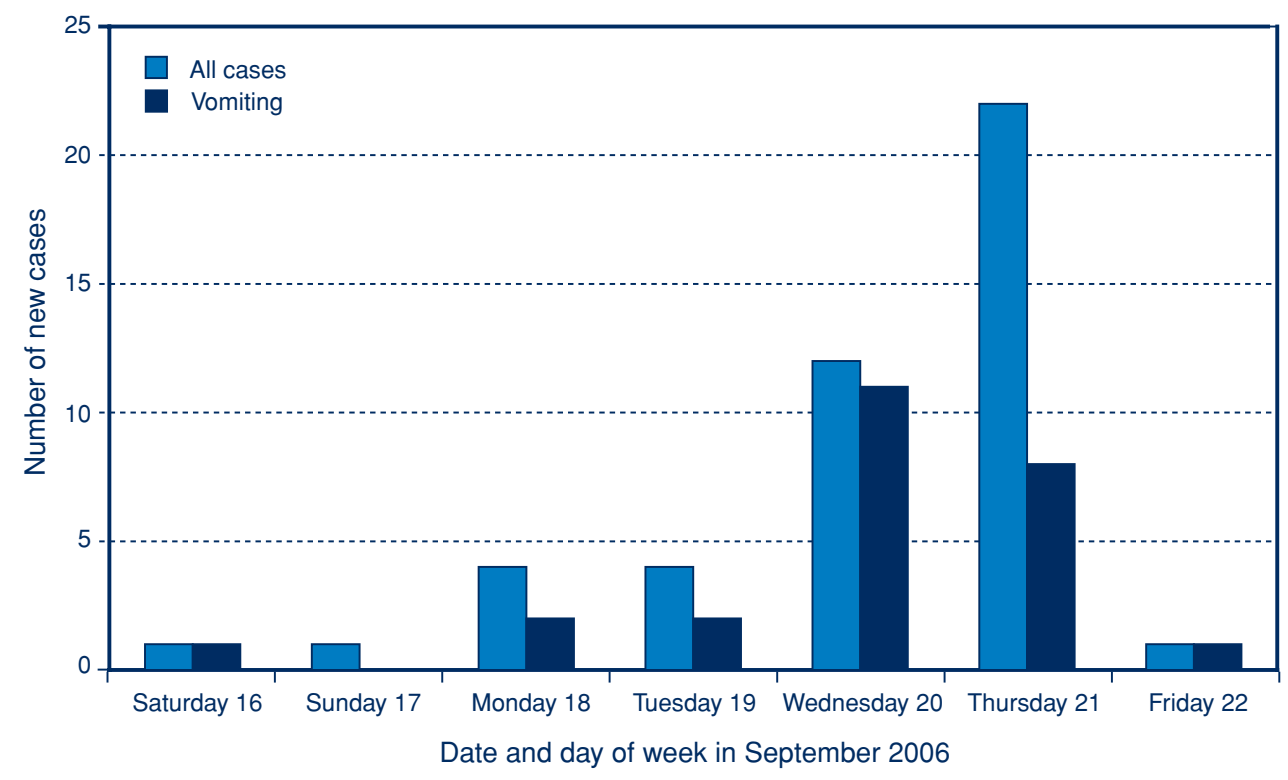

Figure 1. Onset of symptoms among all cases of illness and only those cases reporting vomiting in an outbreak of gastroenteritis in a school music camp, September 2006. Source: PHREDSS, interview and medical record review.

Active surveillance for additional cases through contacting teachers continued up until 29 September. Data were analysed in MS Excel.

\section{Results \\ History of the group obtained by interview}

The students were on a two-week band camp organised through schools in southern Queensland. One hundred school students aged 11 to 18 years were travelling on two buses accompanied by six teachers and four bus drivers. The tour departed from Queensland on 15 September, arriving the next day at a recreation camp in rural NSW. The students stayed at the camp from 16-20 September 2006 and visited Sydney for one day en route to Queensland.

\section{Case identification}

Forty-five cases of gastroenteritis were identified in people on the bus trip, including two teachers, two bus drivers and 41 students. Most onset dates were obtained from triage text fields in PHREDSS and verified through medical record review and interviews. Seven additional cases were identified through interviews with the teacher. The first case occurred on 16 September after the group arrived at the camp and the last case occurred on 22 September (Figure 1). The overall attack rate was 41 per cent $(45 / 110)$ : 41 per cent $(41 / 100)$ in students; 33 per cent $(2 / 6)$ in teachers; and 50 per cent (2/4) in drivers. Thirty-nine people fitting the case definition presented to one of three hospitals.

The most commonly reported symptom was vomiting and/or nausea ( $n=34,76$ per cent) (Table 1$)$. Among the 25 people reporting vomiting, the peak of the epidemic curve occurred on 20 September (11/25 cases, 44 per cent) (Figure 1).

\section{Food and exposure history}

The teacher reported that a variety of takeaway food was consumed at meals en route, except for a barbeque breakfast on 16 September. During the stay all meals were supplied by the camp, with the exception of a barbeque dinner on 19 September. During this meal volunteers cooked meats and students served their own salads from a selfserve area.

Students stayed in shared cabins of between four and eight occupants. Each cabin had its own bathroom.

It was reported that at least one student who became ill early on vomited in shared accommodation, where other students were present. A subsequent case of gastroenteritis occurred in a person who had cleaned vomitus without gloves or other protection.

Table 1. Symptoms experiences by 45 people travelling on a school music camp between 16 and 22 September affected by gastroenteritis

\begin{tabular}{lll}
\hline Symptom & $\boldsymbol{n}$ & $\%$ \\
\hline Nausea & 34 & 76 \\
Abdominal pain or cramp & 29 & 64 \\
Vomiting & 25 & 56 \\
Diarrhoea & 17 & 38 \\
Headache & 11 & 24 \\
Fever & 3 & 7 \\
\hline $\begin{array}{l}\text { Source: teacher interview, case interviews, case notes and public } \\
\text { health real-time emergency department surveillance system } \\
\text { (PHREDSS) triage text. }\end{array}$
\end{tabular}


The recreation camp was inspected on 27 September. The camp is supplied with bore water supplemented with rainwater. Drinking water is filtered, softened and chlorinated. Regular tests recorded by camp staff and an independent laboratory indicate that the drinking water complies with drinking water guidelines. ${ }^{3}$ Samples collected at the site visit also complied with these guidelines.

\section{Laboratory investigation}

All stool samples were negative for any pathogen.

\section{Public health action}

We counselled teachers and students on appropriate infection control measures, including thorough hand washing and cohorting sick people. Teachers were advised against travelling back to Queensland as planned on the evening of 21 September. Emergency accommodation was arranged for the school group in Sydney and a registered nurse was provided to assist with infection control. The group departed by bus on 22 September.

We alerted public health staff in Queensland and the local hospital emergency department of the outbreak before the return of the bus. Active surveillance (to 29 September) identified one additional case with an onset of 22 September.

\section{Discussion}

Despite early reports suggesting an aetiology of a more sinister nature, the epidemiological and symptom profile of this outbreak is consistent with an outbreak of viral gastroenteritis, probably norovirus, with person-to-person transmission.

Initially person-to-person transmission was suspected. Due to the large number of people presenting to emergency departments across Sydney, significant media attention and the fact that the children were 'stranded', an urgent public health response was necessary. A retrospective case series was used to obtain information rapidly, describe the outbreak and inform public health action in a timely manner. This strategy was limited by incomplete case ascertainment at the time - a problem overcome by using real-time emergency department surveillance and medical record review.

Emergency department surveillance systems are usually designed as outbreak detection tools. In addition, PHREDSS was used to provide and verify case details after the outbreak of gastroenteritis had been notified.

No causative agent was identified in this investigation. This may have occurred because insufficient samples were collected or the samples were inadequate. ${ }^{4}$

Norovirus was considered a pathogen likely to be responsible for this outbreak because:
- vomiting and/or nausea were the most commonly reported symptoms in this outbreak

- most cases resolved quickly after onset (characteristic of norovirus $)^{5,6}$

- norovirus is a common cause of gastroenteritis and gastroenteritis outbreaks in older children and adults $^{6-11}$

- the attack rate in this outbreak is typical of outbreaks of norovirus in institutional settings. ${ }^{12-14}$

The epidemic curve for this outbreak is consistent with person-to-person transmission, with a small number of early cases followed by a rapid increase in cases. ${ }^{13,14}$ Probable settings of viral transmission, including shared accommodation, transport and self-service meals, were identified during the interviews. Person-to-food-to-person transmission may have also been involved in this outbreak.

At the peak of the epidemic (on 21 September), reported symptoms may have been exaggerated due to the stress of the incident. Several people presenting to emergency departments experienced only one non-specific symptom: nausea, headache or abdominal pain. The peak of the epidemic curve for those who experienced vomiting actually occurred one day earlier, on 20 September. The outbreak may have been subsiding by the time the mass transfer of cases to hospitals occurred on 21 September.

\section{Conclusion}

This outbreak required significant mobilisation of emergency service, hospital and public health resources. The public health response required communication between two public health units and the NSW Department of Health, as well as with other agencies involved in the provision of emergency assistance to the travelling party. The coordination of the rapid response was aided by the additional data gained from PHREDSS. Such emergency department surveillance systems provide valuable information in public health investigations. This incident could be viewed as a test of the health response to large incidents, such as pandemic influenza and bioterrorism.

\section{Acknowledgements}

We wish to acknowledge the assistance of the following people: public health unit staff in Greater Southern Area Health Service and Chris Oxenford, OzFoodNet epidemiologist, Australian Capital Territory for assistance with the investigation in Sutton and Canberra; and public health unit staff in Sydney South West and South Eastern Sydney Illawarra Area Health Services for assistance with the investigation in Sydney.

\section{References}

1. Muscatello DJ, Churches T, Kaldor J, Zheng W, Chiu C, Correll $\mathrm{P}$ et al. An automated, broad-based, near real-time public health surveillance system using presentations to hospital Emergency Departments in New South Wales, Australia. BMC Public Health 2005; 5: 141. doi:10.1186/14712458-5-141 
2. Ferson MJ, Yankos P, Pontivivo G, Wong A, Lee D, Isaacs M et al. Value of a reverse transcriptase-polymerase chain reaction assay for Norwalk-like viruses in the investigation of institutional gastroenteritis outbreaks. NSW Public Health Bull 1999; 10: 158-60. doi:10.1071/NB99069

3. National Health and Medical Research Council (NHMRC), Agriculture and Resource Management Council of Australia(ARMCA). Australian Drinking Water Guidelines. Canberra; Australian Government, 2004.

4. Vinje J, Vennema H, Maunula L, von Bonsdorff C-H, Hoehne M, Schreier E et al. International collaborative study to compare reverse transcriptase PCR assays for detection and genotyping of noroviruses. J Clin Microbiol 2003; 41(4): 1423-33. doi:10.1128/JCM.41.4.1423-1433.2003

5. Pedalino B, Feely E, McKeown P, Foley B, Smyth B, Moren A. An outbreak of Norwalk-Like viral gastroenteritis in holidaymakers travelling to Andorra, January-February 2002. Euro surveillance 2003; 8(1): 1-7.

6. Heymann DL, ed. Control of Communicable Diseases Manual. 18th ed. Washington DC: American Public Health Association, 2004: pp. 224-7.

7. NSW Public Health Bulletin Communicable diseases report NSW for September and October 2005. N S W Public Health Bull 2005; 16(11-12): 205-11.
8. NSW Public Health Bulletin Communicable diseases report, New South Wales, for March and April, 2006. N S W Public Health Bull 2006; 17(5-6): 90-1.

9. NSW Public Health Bulletin Communicable diseases report, New South Wales, for May-June 2004 N S W Public Health Bull 2006; 15(7-8): 144-5.

10. Dalton C. Foodborne diseases surveillance in NSW: moving towards performance standards. NSW Public Health Bull 2004; 15(1-2): 2-5.

11. Mead PS, Slutsker L, Dietz V, McCaig LF, Bresee JS, Shapiro $\mathrm{C}$ et al. Food related illness and death in the United States. Emerg Infect Dis 1999; 5: 607-25.

12. Conlon L, Pranica K, Donart L, Proctor M, Simone M, Lucht $\mathrm{L}$ et al. Norwalk-Like virus outbreaks at two summer camps - Wisconsin, June 2001. MMWR 2001; 50(30): 642-3.

13. Forssman B, Gupta L, Salmon S. Gastroenteritis outbreak at a residential college linked to a self-serve food bar. $N S W$ Public Health Bull 2005; 16(7-8): 131-40.

14. CDC Norwalk-Like Viruses: Public health consequences and outbreak management. MMWR 2001; 50: 1-18. RR09 